\title{
The Fibrinolytic System and Thrombotic Tendency
}

\author{
C. Kluft
}

Gaubius Laboratory, TNO-PG, Leiden, The Netherlands, and

Department for Thrombosis Research, University of Southern Denmark, Esbjerg, Denmark.

\section{Key-words \\ Fibrinolysis - Plasminogen - Elastase - Cathepsin G . Metalloproteinase - Thrombosis · Wound healing}

abnormalities in the various mechanisms and special situations will lead to fibrin accumulation and thrombotic events.

Copyright (C) 2004 S. Karger AG, Basel

\section{Introduction}

Biological pathways and mechanisms frequently show an organisation where either parallel pathways exist and/or where sequential factors operate. This is schematically illustrated in figure $1 \mathrm{~A}$ and $\mathrm{B}$, where the road from $\mathrm{X}$ to phenotype $\mathrm{Y}$ is either a process catalysed by multiple pathways or factors $(A, B, C)$ or a route with multiple, sequential factors $(A, B, C)$.
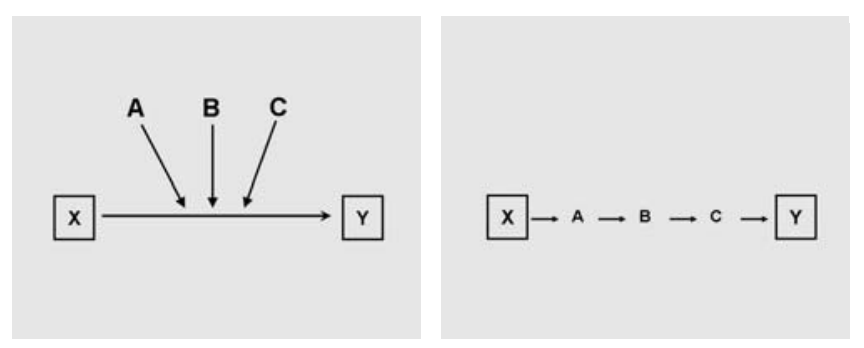

Fig. 1A. Multiple parallel path- Fig. 1B. Multiple factors act ways catalyse the conversion $\mathrm{X}$ to sequentially in the process from $\mathrm{X}$ Y.

\section{KARGER \\ Fax +4161306 1234}

E-Mail: karger@karger.ch www.karger.com

\section{(C) 2004 S. Karger AG, Basel 1424-8832/04/0336-0425\$21.0/0}

Accessible online at: www.krager.com/pht \begin{abstract}
ious buffering mechanisms and only combinations of
Abstract

The deposition of the insoluble protein matrix, fibrin is ic removal is orchestrated by a cascade type of proteolytic process involving ultimately the formation from pasminogen of the active degradation enzyme plas out a massive deposition of fibrin and thrombotic events indicates the occurrence of alternate routes of fibrin degradation. In the literature, data have been reported about the direct fibrinolytic activity of various cathepsin MMP-7, MT1-MMP). The importance of each of these pathways and the possible differences in importance in in the circulation, in tissues and organs is no

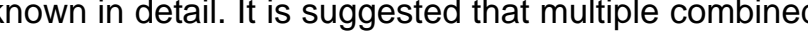

\author{
C. Kluft \\ Gaubius Laboratory, TNO-PG \\ P.O. Box 2215 \\ 2301 CE Leiden, The Netherlands \\ Tel: +31 7151 81497; Fax + 317151 81904; E-mail: c.kluft@pg.tno.nl
}




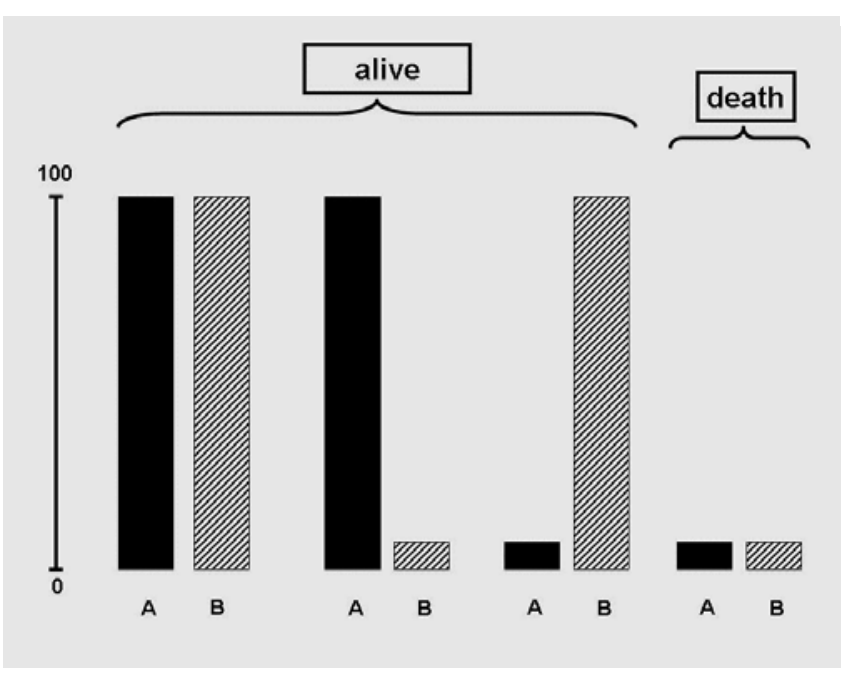

Fig. 2. Synthetic lethal: If an organism is viable with full function of either one of two genes (I or II) and no function of the other; and the organism is not viable when both genes are not functional [1].

For known parallel pathways it has been estimated that many genes have one or two parallel relationships, and a few genes even have 10 or more such interactions [1].

This parallel organisation is also known by the terms "redundancy" or "buffering" or "overlapping functionality". An approach to the analysis of parallel mechanisms for viability is termed "synthetic lethal ".

This is illustrated in figure 2, showing for two parallel pathways the consequences of one or two deficiencies.

The principle of "synthetic lethality" also applies to non- lethal phenotypes, but is more appropriately referred to as redundancy, buffering or overlapping functionality.

Sequential pathways are for instance known from cellular metabolisms (e.g. cholesterol synthesis), and from the pathways leading from trigger to inflammation [2]. When not buffered by a parallel pathway, defects in a single factor in a sequential pathway may block a whole pathway and partial, quantitative abnormalities in multiple factors weaken the pathway as a whole. Critical factors may exist and may have a relatively large impact.

\section{Fibrinolysis}

In the fibrinolytic system we have at the level of plasminogen activation several parallel pathways such as the contact pathway, the u-PA and the t-PA pathways, and in addition we may include the involvement of plasmin in the activation of metalloproteinases [3]. This may in particular be of relevance for MMP-9, which binds to fibrin and becomes activated in a plasmin-dependent manner [4].

Parallel pathways do also exist at the level of direct proteolytic fibrin dissolution or plasmin.

For the inhibition of fibrinolysis we also have for each pathway multiple mechanisms that may buffer each other. For the plasminogen activation pathway and plasmin we can consider plasmin inhibitor, plasminogen activator inhibitor 1 (PAI-1), thrombin-activatable fibrinolysis inhibitor (TAFI) and Factor XIII as contributors to prolonged fibrin existence.

Interestingly, among the inhibitors, all depend in action

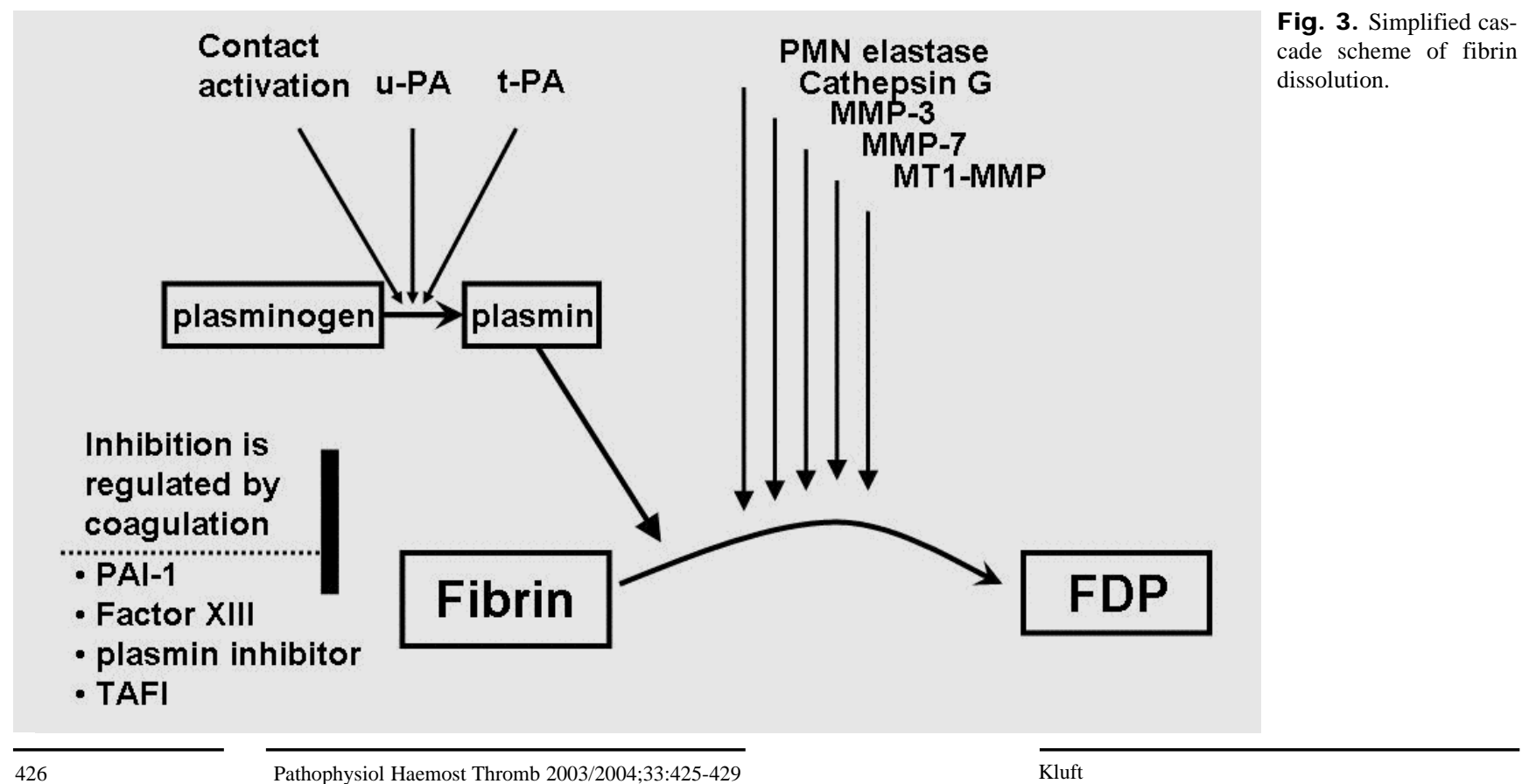


or efficacy in action upon sequential pathways originating from coagulation activation. Notably, factor XIII becomes activated by coagulation, plasmin inhibitor becomes bound to fibrin by factor XIII, PAI-1 becomes released by platelet activation and TAFI is activated by thrombin-thrombomodulin.

We will discuss further the parallel pathways at the direct proteolytic or plasmin level in more detail.

\section{Parallel Pathways at the Plasmin Level}

At the level of fibrin degradation we have information that more than one parallel pathway exists. This information stems from animal and human data where deficiency in plasminogen has not been found to be associated with dominant thrombotic tendencies as could have been expected from a failing fibrinolysis [5].

This points to other mechanisms capable of fibrin digestion without plasminogen mediation. In the literature such possibilities have been demonstrated for leucocytal proteases (elastase and cathepsin G) and for three metalloproteinases (cf. figure 3).

The importance of leukocytes, polymorphonuclear leukocytes (PMNs), for fibrin dissolution has long been known. Upon fibrin formation, PMNs are trapped, but more importantly, accumulate later (predominantly during the first $12 \mathrm{~h}$ ) and penetrate thrombi [6] showing, according to Henry [7], between 4 to $13 \mathrm{~h}$ after clot formation an 11 to 14 times higher number in clots compared to circulating blood. Barnhart [8] distinguished three contributions of these cells to the disappearance of the fibrin: (a) mechanical thrombolytic mechanisms involving the dissociation of the organisation of a thrombus due to the migration/mobility of the PMNs in the clot; (b) phagocytosis of fibrin material and intracellular digestion; and (c) release of enzymes by exocytosis, coagulation activation or cell death, with (mainly relevant for fibrinolysis) the elastase-like proteinase (PMNelastase) and the chymotrypsin-like proteinase (cathepsin $\mathrm{G})$. The participation of PMNs in fibrinolysis is witnessed by circulating cells showing intracellular fibrin-related antigen only after an event of fibrin formation [8].

Further detailed biochemical work has identified both enzymes mentioned as the major (>95\%) fibrinolytic proteases of human leukocytes [9], and also shown evidence for elastase-specific fibrin(ogen) degradation products in the circulation in certain pathological conditions [10]. A baseline level of fibrin(ogen) degradation products from elastase has also been detected in healthy volunteers [11].

Fibrin can also be solubilised directly by metalloproteinases. Bini et al showed the action of MMP-3 (stromelysin-1) on cross-linked fibrin to be specific and different from plasmin, resulting in a D-like monomer frag-

The fibrinolytic System and Thrombotic Tendency ment [12]. The two MMPs, MMP-7 (matrilysin) and MT1MMP (membrane type 1 matrix MP) solubilised crosslinked fibrin as well, however, yielding D-dimer fragments of similar molecular mass to the plasmin product [13].

\section{Discussion}

The occurrence of multiple pathways for the dissolution of deposited fibrin points to the importance of the removal of fibrin and/or to the multiple functions of fibrin. Multiple functions of fibrin have been recognised in providing a haemostatic plug and in providing a temporary matrix for tissue repair.

The further consequences of the occurrence of multiple pathways are that only large deviations in one of the pathways or combinations of deviations in multiple pathways will lead to clinically relevant abnormalities.

These abnormalities may be diverse. The relative importance of multiple pathways may be different for various phenotypes such as vascular fibrin formation and tissue repair, dependent upon localisation and dependent upon systemic conditions such as strong inflammation.

Plasminogen deficiency is characterised by ligneous conjunctivitis, a rare form of chronic conjunctivitis where firm fibrin-rich, woody-like pseudomembraneous lesions develop mainly in the tarsal conjunctivae. Less frequently, similar lesions may occur in other mucous membranes of the body [5]. Symptoms are similar in plasminogen-deficient mice but absent in mice doubly deficient in both plasminogen and fibrinogen, demonstrating the importance of fibrin in the process [14].

\section{Lysis of Intravascular Fibrin}

In vascular fibrin dissolution the roles of the plasminogen-plasmin system and of PMN proteases are likely to dominate.

In vascular fibrin dissolution the contribution of PMN proteases is expected to be at later stages after a thrombotic challenge when PMNs have accumulated in the fibrin (see above). In studies of plasminogen-deficient mice an increased contribution of PMNs was anticipated and evidence of a larger contribution has indeed been obtained [15]. The single knock-out in PMN elastase and cathepsin G, or combined deficiencies in the beige mice [16] do not show a phenotype suggestive of fibrin accumulation or thrombotic tendencies $[17,18]$. The combination of plasminogen deficiency with either PMN-elastase or cathepsin G or both deficiencies will disclose the importance of each contribution to fibrin dissolution in models with specific thrombotic challenges, and disclose whether or not another contribution may exist.

\footnotetext{
Pathophysiol Haemost Thromb 2003/2004;33:425-429
} 
In plasminogen-deficient humans the composition of circulating fibrin degradation products and the fibrin content of leucocytes may provide further information on the degree of contribution of this pathway to fibrin removal.

The contribution of MMPs to vascular fibrinolysis is not expected to be large, but can be disclosed experimentally by the inhibition of all MMPs with inhibitors, such as galardin, elegantly used for studies of functional overlap in wound healing [19]. Alternatively, knock-out mice for the separate MMPs, which are available [20-22] may be used to disclose the contribution of each specific MMP. However, detailed experiments and a diversity of clinical phenotype analyses in mice with various genetic backgrounds are required to detail the importance of MMPs relative to plasmin and PMN leucocytal proteases.

The demand for fibrin dissolution and the participating mechanisms may change under different conditions. An example of this is sepsis and multitrauma. Under these conditions the trauma results in very strong increases in the inhibitor of plasminogen activation PAI-1 and its increased levels associated with the $4 \mathrm{G}$ allele of the PAI- 1 gene are associated with a less favourable outcome [23, 24]. It indicates an important role of plasminogen-related dissolution of vascular fibrin in cases with strong trauma. It is suggestive of an important risk for plasminogen-deficient individuals in cases of sepsis and multitrauma of developing excessive vascular fibrin deposition. In the presently known cases the predominant expression is as ligneous conjunctivitis, indicating a lack of buffering mechanism particularly in the mucous membranes.

\section{Extravascular Fibrin Dissolution}

In extravascular fibrin dissolution during tissue remodelling MMPs of cellular origin are expected to play an important role. In the available information a role for MMPs in fibrin dissolution and in other proteolytic processes cannot be isolated with certainty, but data on MMP-3 and MT1MMP suggest a role in fibrin dissolution in vivo.

MMP-3 deficient mice show slow healing of excisional wounds [20] and in a model of wound healing the inhibition of MMPs with galardin combined with a deficiency in plas- minogen appears to be "synthetic lethal" for wound repair [19]. The observation that in TAFI-deficient mice wound healing is impaired [25], indicates together with the above observation on MMP-3-deficient mice that both the plasminogen-plasmin system and MMPs play a role in proper wound healing and do not fully buffer each other. Functional overlap between plasminogen activation and MMP action was also apparent in tubule formation in angiogenesis [26] and vascularisation during placental development [27]. More detailed involvement of MMP3, MMP-7, MT1-MMP in extravascular fibrin dissolution may be disclosed by the specific use of combinations of deficient animals, including fibrinogen deficiency.

Interestingly, also cathepsin G-deficient mice show impaired wound healing at early stages [28] indicating leukocyte involvement or the involvement of cathepsin $G$ from other sources.

\section{Conclusions}

Fibrin dissolution is achieved by several mechanisms acting in parallel which can partially compensate for each others malfunction. The degree of compensation is dependent upon the exact localisation of the fibrin and 'the condition of the organisms. Not all mechanisms and their relative potencies are known with certainty, but may be further disclosed by using various combinations of deficiencies in transgenic animals.

A thrombotic tendency is expected to be the consequence of multiple factors and combined malfunctions. Laboratory diagnostic procedures to evaluate a thrombotic tendency should not be restricted to clotting and traditional plasminogen-dependent fibrinolysis [29], but be extended to the other systems of fibrin dissolution.

Impaired fibrin removal in tissue repair and modelling may show unexpected clinical expression such as ligneous conjunctivitis with plasminogen deficiency.

\section{References}

1 Hartman IV JL, Garvik B, Hartwell L. Principles for the buffering of genetic variation. Science 2001;291:1001-1004.

2 Kluft C, de Maat MP. Genetics of C-reactive protein: new possibilities and complications. Arterioscler Thromb Vasc Biol 2003;23:19561959.
Lijnen HR. Matrix metalloproteinases and cellular fibrinolytic activity. Biochemistry 2002;67:92-98. Makowski GS, Ramsby ML. Binding of latent metalloproteinase 9 to fibrin: activation via a plasmin-dependent pathway. Inflammation 1998;22. 287-305.
Schuster V, Seregard S. Ligneous conjunctivitis. Surv Ophthalmol 2003;48:369-388.

6 Gottlob R, Mattausch M, Porschinski K, Kramar $\mathrm{R}$. The possible role of leukocytes in spontaneous and induced thrombolysis and some properties of leukocyte proteinase. In: Progress in Chemical Fibrinolysis and Thrombolysis, (Davidson JF, Rowan RM, Samama MM, Desnoyers PC, eds.) Raven Press, New York vol 3; 1978, 391-397. 
7 Henry RL. Leukocytes and thrombosis. Thromb Diath Haemorrh 1965;13:35-46.

8 Barnhart MI. Importance of neutrophilic leukocytes in the resolution of fibrin. Fed Proc 1965; 24:846-853.

9 Plow EF. The major fibrinolytic proteases of human leukocytes. Biochim Biophys Acta 1980; 630:47-56.

10 Plow EF. The contribution of leukocyte proteases to fibrinolysis. Blut 1986;53:1-9.

11 Bos R, van Leuven CJ, Stolk J, Hiemstra PS, Ronday HK, Nieuwenhuizen W. An enzyme immunoassay for polymorphonuclear leucocytemediated fibrinogenolysis. Eur J Clin Invest 1997; 27:148-156.

12 Bini A, Itoh Y, Kudryk BJ, Nagase H. Degradation of cross-linked fibrin by matrix metalloproteinase 3 (stromelysis-1): hydrolysis of the gamma Gly 404-Ala 405 peptide bond. Biochemistry 1996; 35:13056-13063.

13 Bini A, Wu D, Schnuer J, Kudryk BJ. Characterization of stromelysin-1 (MMP-3), matrilysin (MMP-7), and membrane type 1 matrix metalloproteinase (M1T-MMP) derived fibrin(ogen) fragments D-dimer and D-like monomer: NH2-terminal sequences of late-stage digest fragments. Biochemistry 1999;38:1392813936.

14 Drew AF, Kaufman AH, Kombrinck KW, Danton MJ, Daugherty CC, Degen JL, Bugge TH. Ligneous conjunctivitis in plasminogen-deficient mice. Blood 1998;91:1616-1624

15 Zeng B, Bruce D, Kril J, Ploplis V, Freedman B, Brieger D. Influence of plasminogen deficiency on the contribution of polymorphonuclear leucocytes to fibrin/ogenolysis: studies in plasminogen knock-out mice. Thromb haemost 2002;88:805810.
16 Takeuchi K, Wood H, Swank RT. Lysosomal elastase and cathepsin $\mathrm{G}$ in beige mice. Neutrophils of beige (Chediak-Higashi) mice selectively lack lysosomal elastase and cathepsin G. J Exp Med 1986;163:665-677.

17 Hirche TO, Atkinson JJ, Bahr S, Belaaouaj A Deficiency in neutrophil elastase does not impair neutrophil recruitment to inflamed sites. Am J Resp Cell Mol Biol 2004;30:576-584.

18 MacIvor DM, Shapiro SD, Pham CT, Belaaouaj A, Abraham SN, Ley TJ. Normal neutrophil function in cathepsin G-deficient mice. Blood 1999;94: 4282-4293.

19 Lund LR, Romer J, Bugge TH, Nielsen BS, Frandsen TL, Degen JL, Stephens RW, Dano K. Functional overlap between two classes of matrixdegrading proteases in wound healing. EMBO J 1999;18:4645-4656.

20 Bullard KM, Lund L, Mudge JS, Mellin TN, Hun TK, Murphy B, Ronan J, Werb Z, Banck MJ. Impaired wound contraction in stromelysin-1 deficient mice. Ann Surg 1999;230:260-265.

21 Ugwu F, Lemmens G, Collen D, Lijnen HR. Matrix metalloproteinase deficiencies do not impair cell-associated fibrinolytic activity. Thromb Res 2001;102:61-69.

22 Hotary KB, Yana I, Sabeh F, Li XY, Holmbeck K Birkedal-Hansen H, Allen ED, Hiraoka N, Weiss SJ. Matrix metalloproteinases (MMPs) regulate fibrin-invasive activity via MT1-MMP-dependent and -independent processes. J Exp Med 2002;195: 295-308.

23 Hermans PW, Hibberd ML, Booy R, Daramola O, Hazelzet JA, de Groot R, Levin M. 4G/5G promoter polymorphism in the plasminogen-activator-inhibitor-1 gene and outcome of meningococcal disease. Meningococcal Research Group. Lancet 1999;354:556-560.
24 Menges T, Hermans PW, Little SG, Langefeld T, Boning $\mathrm{O}$, Engel J, Sluijter $\mathrm{M}$, de Groot $\mathrm{R}$, Hempelmann G. Plasminogen-activator-inhibitor1 4G/5G promoter polymorphism and prognosis of severely injured patients. Lancet 2001;357: 1096-1097.

25 Te Velde EA, Wagenaar GT, Reijerkerk A, RooseGirma M, Borel Rinkes IH, Voest EE, Bouma BN, Gebbink MF, Meijers JC. Impaired healing of cutaneous wounds and colonic anatomoses in mice lacking thrombin-activatable fibrinolysis inhibitor. J Thromb Haemost 2003;1:2087-2096.

26 Collen A, Hanemaayer R, Lupu F, Quax PH, Van Lent N, Grimbergen J, Peters E, Koolwijk P, van Hinsbergh VW. Membrane-type matrix metalloproteinase-mediated angiogenesis in a fibrin-collagen matrix. Blood 2003;101:1810-1817.

-27 Solberg H, Rinkenberger J, Dano K, Werb Z, Lund LR. A functional overlap of plasminogen and MMPs regulates vascularization during placental development. Development 2003;130: 4439-4450.

28 Abbott RE, Corral CJ, MacIvor DM, Lin X, Ley TJ, Mustoe TA. Augmented inflammatory responses and altered wound healing in cathepsin G-deficient mice. Arch Surg 1998;133:1002-1006.

29 Scott BT, Bovill EG, Callas PW, Hasstedt SJ, Leppert MF, Valliere JE, Varvil TS, Long GL. Genetic screening of candidate genes for a prothrombotic interaction with type I protein $\mathrm{C}$ deficiency in a large kindred. Thromb Haemost 2001; 85:82-87. 